\title{
A High Oil Content Genetic Stock (HOSuS-1) of Sunflower (Helianthus annuus L.) Developed through Introduction and Selection
}

\author{
M. Sujatha*, M. Y. Dudhe, H. P. Meena and Praduman Yadav
}

ICAR-Indian Institute of Oilseeds Research, Hyderabad-500 030, Telangana, India

*Corresponding author

\section{A B S T R A C T}

\begin{tabular}{l} 
Ke y w o r d s \\
Genetic Stock \\
(HOSuS-1), \\
Sunflower, \\
Helianthus annuus \\
\hline Article Info \\
$\begin{array}{l}\text { Accepted: } \\
04 \text { October } 2020 \\
\text { Available Online: } \\
10 \text { November } 2020\end{array}$ \\
\hline
\end{tabular}

\section{Introduction}

Sunflower (Helianthus annuus L.), a native of America was introduced as a commercial oilseed crop in India during 1970s. The genus Helianthus includes 52 species (67 total taxa) (Kane et al., 2013), occupying prime position in the Indian economy. In India, the crop has witnessed a considerable growth in terms of area and production since. It is also called Surajmukhi, Suryaphula, Suryakanti, Poddutirugudu, Curiyakanti, Suryamukhi, etc. The relative photo and thermo-insensitivity of the crop makes it an ideal crop that fits well in many multiple and intercropping systems in a wide range of agro-climatic conditions both as catch crop as well as contingency crop
(Prabakaran, 2009). Karnataka, Andhra Pradesh, Maharashtra and Tamil Nadu are the major traditional sunflower growing states. Following the release of BSH-1 (CMS-234A $x$ RHA-274), the first sunflower hybrid in India in 1980 a total of 29 hybrids suitable for different agro-climatic conditions were released (Sujatha et al., 2019). One of the objectives in developing sunflower hybrids is improved oil content (Dedio, 1993). Development of parental lines, inbreds and hybrids with high oil content is one of the breeding priorities in India where the crop is predominantly raised in a tropical environment. In view of this and great prospect of cultivation of this crop successfully in various region of India, it is 
necessary to develop high oil yielding hybrids for different locations or agro-climatic conditions. Sunflower breeding programs in most of the countries including India have traditionally selected high oil male and female lines from populations or crosses to produce hybrids with improved oil content, based on the assumption that the high oil trait in the parental lines is manifested in the hybrid. Keeping in view the comparatively low oil content in most of the parental lines exploited in heterosis breeding programmes, an attempt has been made to develop inbreds with high oil content through selection.

\section{Materials and Methods}

The high oil content line HOSuS-1 is a selection from segregating progenies of the germplasm accession $\mathrm{GP}_{4}-1424$ of cultivated sunflower imported from Russia. This line was developed mainly for high oil content through introduction and selection method at ICAR-Indian Institute of Oilseeds Research, Rajendranagar, Hyderabad.

The experiment was conducted in augmented block design along with checks during kharif 2015, rabi 2018, 2019 and 2020. Each genotype was represented by two rows of 4.5 m length with $60 \times 30 \mathrm{~cm}$ spacing between and within rows, respectively. Recommended packages and practices were followed to raise the healthy crop. Oil content observation was analysed through Nuclear Magnetic Resonance (NMR) during the years 2015, 2018, 2019 and 2020, respectively and compared with RHA-6D-1 and DRSH-1 as checks and confirmed through Soxhlet to know the potential of the line. Other morphoagronomic characters like plant height $(\mathrm{cm})$, head diameter $(\mathrm{cm})$, days to flowering, days to maturity, seed colour, pollen colour, 100 seed weight $(\mathrm{g})$, volume weight $(\mathrm{g} / 100 \mathrm{ml})$, leaf blistering and leaf petiole pigmentation were also recorded.

\section{Results and Discussion}

The oil content of sunflower achenes depends on a combination of hull percentage and oil percentage in the kernel with hull content reported to be the more important factor (Gundaev, 1971). The oil content in the achene of the genotype is thus determined by the combination of content of oil in the kernel and by the content of kernel itself. Newly developed line HOSuS-1 was promising for oil content recording $>40 \%$ consistently (Anonymous, 2018-19). The average oil content of this line was $41.32 \%$ compared to high oil content check RHA-6D-1 (37.9\%) (Table 1). The $\mathrm{P}$ test value showed no difference in oil content between replications. Oil content data of newly developed lines confirmed through Soxhlet is presented in Table 2. The newly developed line can be utilized for development of high oil content gene pool, inbreds, parental lines and hybrids. Putt (1966) and Fick (1975) reported an increase of $30 \mathrm{~g}$ oil $/ \mathrm{kg}$ achenes in the hybrids over the mid-parent values. HOSuS-1 is characterized for different morpho-agronomic characters which are presented in Table 3. Branching and non-branching types of genotype is very useful in sunflower breeding programme. Branching type is mostly used as male parent in heterosis breeding but now a days sunflower breeders prefer non-branching line as a male parent due to its easy maintenance. The plants were unbranched, medium in maturity (83 days), medium in plant height $(105 \mathrm{~cm})$ with slender stems. Different morphological traits are very useful for characterization of breeding materials. Leaves and stems were smooth and nonpubescent. Leaves were large and green with triangular shape. Medium blistering was present on leaves without petiole pigmentation. The stem pigmentation was absent. The ray florets were many in number with elongated shape. The ray floret colour was yellow. It is used as morphological 
marker to characterize and identify the genotype.

Table.1 Oil content data of four years through NMR

\begin{tabular}{|c|c|c|c|}
\hline \multirow{2}{*}{ S. No. } & \multirow{2}{*}{ Year } & \multicolumn{2}{|c|}{ Oil content (\%) } \\
\cline { 3 - 4 } & & HOSuS-1 (GP-1424 selection) & RHA-6D-1/DRSH-1 (Check) \\
\hline $\mathbf{1 .}$ & 2015 & 41.78 & 34.94 \\
\hline $\mathbf{2 .}$ & 2018 & 41.52 & $29.82^{*}$ \\
\hline $\mathbf{3 .}$ & 2019 & 40.74 & 40.71 \\
\hline $\mathbf{4 .}$ & 2020 & 41.26 & 36.65 \\
\hline & Mean & $\mathbf{4 1 . 3 2}$ & $\mathbf{3 5 . 5 4}$ \\
\hline & SD & $\mathbf{0 . 4 4}$ & \\
\hline & SE \pm & $\mathbf{0 . 2 2}$ & \\
\hline
\end{tabular}

*DRSH-1

Table.2 Soxhlet oil content data (2020)

\begin{tabular}{|c|l|c|c|}
\hline S. No. & \multicolumn{1}{|c|}{ Genotype } & \multicolumn{2}{|c|}{ Oil content (\%) } \\
& & \multicolumn{1}{|c|}{ through Soxhlet method } \\
\hline $\mathbf{1 .}$ & RHA-6D-1(check for oil content) & 37.56 & 37.94 \\
\hline $\mathbf{2 .}$ & DRSH-1 (hybrid check for oil content) & 39.12 & 38.54 \\
\hline $\mathbf{3 .}$ & HOSuS-1 (GP 4 -1424 selection) & $\mathbf{4 2 . 1 0}$ & $\mathbf{4 1 . 7 3}$ \\
\hline & Mean & $\mathbf{3 9 . 4 9}$ & \\
\hline & SD & $\mathbf{2 . 3 1}$ & \\
\hline & SE \pm & $\mathbf{1 . 3 3}$ & \\
\hline & P value & $\mathbf{0 . 9 2}$ & \\
\hline
\end{tabular}

Table.3 Morpho-agronomic characteristics of HOSuS-1

\begin{tabular}{|c|l|c|}
\hline S. No. & Characteristics & Description \\
\hline $\mathbf{1}$ & Plant height $(\mathrm{cm})$ & 105.0 \\
\hline $\mathbf{2}$ & Head diameter $(\mathrm{cm})$ & 11.4 \\
\hline $\mathbf{3}$ & Days to flowering & 53 \\
\hline $\mathbf{4}$ & Days to maturity & 83 \\
\hline $\mathbf{5}$ & Seed colour & Black \\
\hline $\mathbf{6}$ & Pollen colour & Yellow \\
\hline $\mathbf{7}$ & 100 seed weight $(\mathrm{g})$ & 3.9 \\
\hline $\mathbf{8}$ & Volume weight $(\mathrm{g} / 100 \mathrm{ml})$ & 44.0 \\
\hline $\mathbf{9}$ & Average oil content $(\%)$ & 41.32 \\
\hline $\mathbf{1 0}$ & Leaf blistering & Medium \\
\hline $\mathbf{1 1}$ & Leaf petiole pigmentation & Absent \\
\hline
\end{tabular}

There are two types of disc florets colour viz., orange or yellow and purple are there in sunflower. The disc floret colour in the newly developed line HOSuS-1 was orange without pigmentation. Head attitude and head shape from grain side are very important characters. 
The head attitude of the line was half-turned down with flat shape and small size (11.4 $\mathrm{cm})$. Mostly breeders preferred only halfturned down head attitude and flat to little convex head shape in sunflower. The bract shape of the genotype was elongated without pigmentation. Seed base colour and seed shape are very important characters. Seed base colour was black with ovoid elongated shape. Average seed yield of the line was 24.0 $\mathrm{g} /$ plant with test weight of $3.9 \mathrm{~g}$ and volume weight $44.0 \mathrm{~g}$. There is positive correlation between volume weight and oil content in sunflower. The high oil content genotypes are always preferred by sunflower researchers for development of high oil content inbreds and high oil yielding hybrids. Average oil content of the line was $41.32 \%$ and can be exploited in the sunflower breeding programmes.

In conclusion this genetic stock is high oil content and medium maturing and is recommended for utilization in heterosis breeding programme for development of high oil yielding hybrids, inbreds and parental lines.

\section{References}

Anonymous 2018-19. ICAR-Indian Institute of Oilseeds Research, Rajendranagar, Hyderabad, pp.13.

Dedio, W. 1993. Heterosis and prediction of achene oil content in sunflower hybrids from parental lines. Can. J. Plant Sci., 73: 737-742.

Fick, G.N. 1975. Heritability of oil content in sunflowers. Crop Sci., 15: 77-78.

Gundaev, A.I. 1971. Basic principles of sunflower selection. Pages 417-465 in Genetic principles of plant selection. Nauka, Moscow, Russia.

Kane, N.C., Burke, J.M., Marek, L., Seiler, G., Vear, F., Baute, G., Knapp, S.J., Vincourt, P. and Rieseberg, L.H. 2013. Sunflower genetic, genomic and ecological resources. Mol. Ecol. Resour., 13: 10-20.

Prabakaran, A.J. 2009. Hybrid seed production in sunflower, castor and safflower: principles and achievements. Directorate of Oilseeds Research, Rajendranagar, Hyderabad. pp 1-9.

Putt, E.D. 1966. Heterosis, combining ability, and predicted synthetics from a diallel cross in sunflowers (Helianthus annuus L.). Can. J. Plant Sci., 46: 5967.

Sujatha, M., Meena, H. P., Mukta, N. and Vishnuvardhan Reddy, A. 2019. Varieties and hybrids of sunflower, ICAR-Indian Institute of Oilseeds Research, Hyderabad, pp: 60.

\section{How to cite this article:}

Sujatha, M., M. Y. Dudhe, H. P. Meena and Praduman Yadav. 2020. A High Oil Content Genetic Stock (HOSuS-1) of Sunflower (Helianthus annuus L.) Developed through Introduction and Selection. Int.J.Curr.Microbiol.App.Sci. 9(11): 118-121. doi: https://doi.org/10.20546/ijcmas.2020.911.013 